\title{
Fersis-Phage against Purulent-Inflammatory (Staphylococcal, Streptococca) Pathologies
}

\author{
Gabisonia T*, Giorgadze I, Topuria N, Chanishvili L, Nadiradze M, Chakhunashvili N, Katamadze T, \\ Loladze M, Tamarashvili N, Alibega Svili M, Kalandarishvili T and Eliava T
}

Institut mikrobiologii i virusologii, Tbilisi, Georgia

*Corresponding author: Gabisonia T, Head of the laboratory of applied microbiology, Institut mikrobiologii i virusologii, Tbilisi, Georgia, Tel: 995 577 423225; E-mail: tato_gabisonia@yahoo.co.uk

Received date: January 25, 2019; Accepted date: February 20, 2019; Published date: February 26, 2019

Citation: Gabisonia T, Giorgadze I, Topuria N, Chanishvili L, Nadiradze M, et al. (2019) Fersis-Phage against Purulent-Inflammatory (Staphylococcal, Streptococcal) Pathologies. Arch Clin Microbiol Vol. 10 No. 1:89

Copyright: (c) 2019 Gabisonia T, et al. This is an open-access article distributed under the terms of the Creative Commons Attribution License, which permits unrestricted use, distribution, and reproduction in any medium, provided the original author and source are credited.

\section{Abstract}

The problem of prevention and treatment of infectious diseases in infectious and non-infectious clinics is one of the priorities in practical public health. The application of phage preparations, as antimicrobial medioprophylactic remedies against staphylo- and streptococcal infections seems to be an alternative to antibiotics and sulfonamide preparations. Pronounced tendency of circulating pathogenic bacterial strains towards reducing sensitivity to antibiotics, also caused by irrational use of the latter, further confirmed our decision to create a new phage preparation. Based on the conducted studies the new variant of Fersis, an active, multivalent phage preparation, consisting phages against staphylococci (S. aureus, S. epidermidis) and streptococci (S. pyogenes, $S$. viridians, $S$. sanguis, $S$. salivarius, $S$. agalacticae) causing oral cavity infectious diseases, has been prepared.

\section{Keywords: Staphylococcus; Streptococcus; Bacteriophage;} Phage preparation Fersis

\section{Introduction}

In clinical medicine, special attention is paid to purulent infections, which retain a leading role in human dental infectious pathology. The infection is a causative not only various inflammatory diseases, but also numerous complications such as periodontitis, gingivitis, stomatitis etc.

The most common etiological agents that cause purulentinflammatory diseases are staphylo- and streptococci.

The spectrum of staphylococcal diseases is very wide, since in any part of the body where staphylococcus invades, a pathological process can form. There are many species of staphylococcus known [1]; however, two species-S. aureus and $S$. epidermidis-predominate in humans.

Streptococcus, namely S. pyogenes for a number of characters are closer to pathogenic bacteria, causing not only sporadic, but also group diseases. Pyogenic streptococcus is the causative agent of pyogenic invasions of the mucous membranes, skin and deep tissues. A typical expression of invasion is phlegmon. In the last decade of the twentieth century, there was a return of invasive streptococcal infection, characteristic of the 20s of the century. The reason for the prevalence of pathogenic streptococci is immunodeficiency state among people and ecological problems [2-4]. However, it should be noted that along with mono infection, complex mixed infections are very common.

Antibiotic resistance in human pathogenic bacteria is a threat to public health that has grown immensely in the last years. It is therefore all the more urgent to secure alternative treatment strategies. Phage therapy is one of the alternatives to antibiotics that for a long time has been underexplored in medicine $[5,6]$.

Phage therapy, the use of phages to cure bacterial infections, has received much attention in recent years due to the emergence and rapid spread of antibiotics resistance. In fact, resistance genes towards last resort treatments for multidrugresistant bacteria are reported to be circulating all around the world. This highlights an urgent need to coordinate a global effort in the search for antibiotics adjuvants or alternative improved treatments [7].

The successful use of phage preparations as antimicrobial medio prophylactic remedies, with staphylococcosis and streptococcal oral cavity infections, seems to be alternative to antibiotics and sulphanilamide preparations. Scientific research has been published on phage therapy, and review articles are of particular interest [8-11].

In the study of bacterial flora of the oral cavity, along with mono infection, mixed staphylo- and streptococcal infections often occur in parallel. The association of these two microbes caused complex forms of diseases and antibiotic resistance was expressed most clearly.

The aim of the presented work was production of new, the most optimal phage preparation Fersis (staphylococcal and streptococcal)-highly active, multivalent, purified diphage with 
wide range of action for local and oral administration, during infections such as periodontitis, gingivitis, stomatitis etc.

\section{Materials and Methods}

Strains of staphylococci and streptococci, which cause pathological process in the human body, were isolated from patients with periodontitis, gingivitis and stomatitis diseases. The strains occurred in association (simultaneously) and in case of staphylococci belonged mainly to the following species: $S$. aureus, S. epidermidis and S. saprophyticus and in case of streptococci: S. pyogenes, S. sanguis, S. salivarius, and $S$. agalacticae.

To isolate and identify the causative agent of the disease, the most common bacterial identification methods- microbiological, biochemical, serological and API system were used (Figures 1-3) [12].

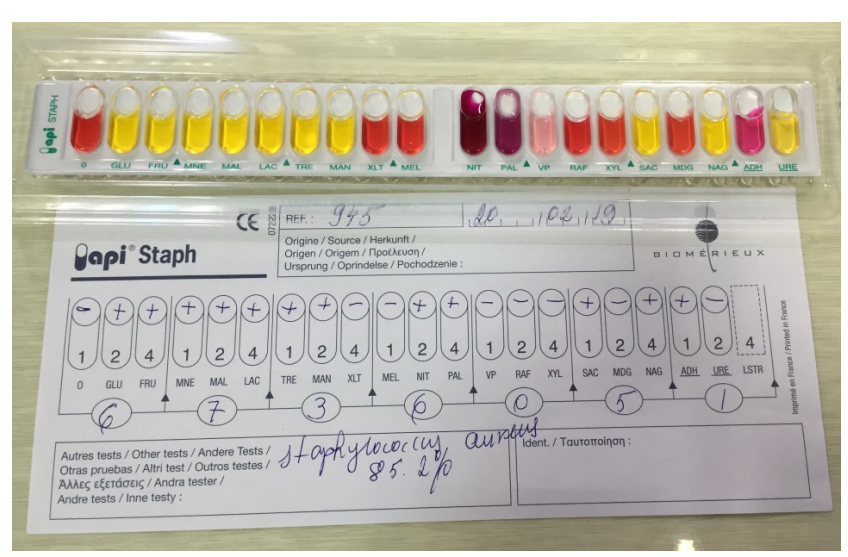

Figure 1. Using API system for diagnostics of Staphylococcus aureus streins.

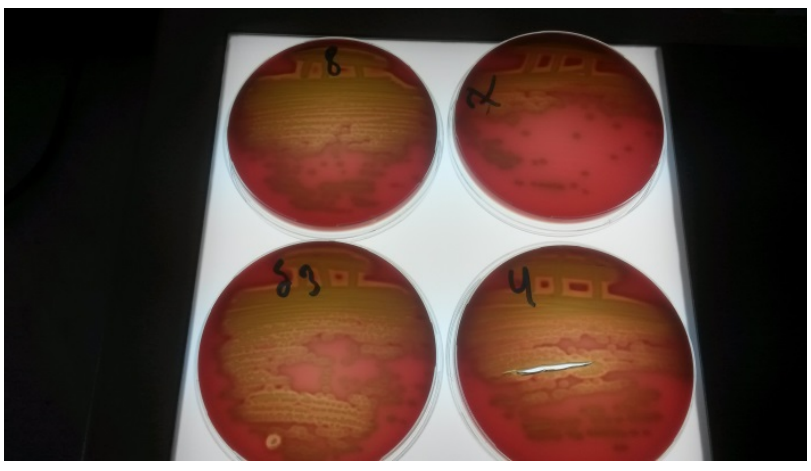

Figure 2. Hemolytic activity of Staphylococcus aureus strains isolated from oral cavity.

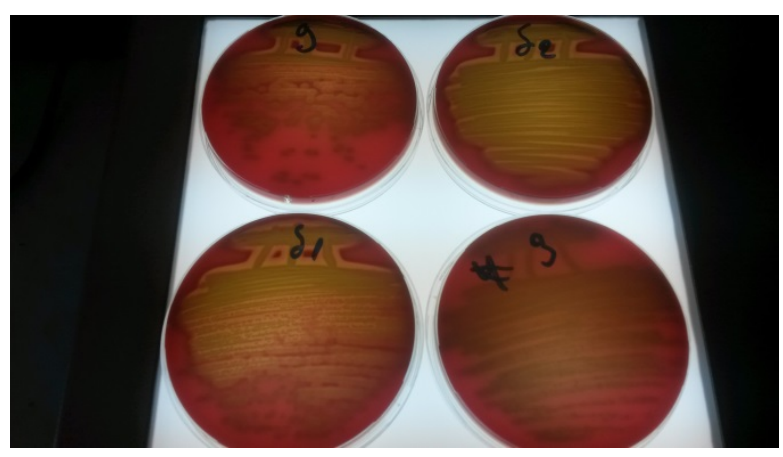

Figure 3. Hemolytic activity of Streptococcus pyogenes strains isolated from oral cavity.

Determination of phage sensitivity of freshly isolated clinical and standard microorganisms was carried out using a technique modified.

The antibiotic sensitivity of Staphylococcus and Streptococcus strains isolated during oral infectious pathologies have been studied for the following antibiotics: Ampicillin, Gentamicin, Kanamicin, Penicillin, Streptomycin and Tetracycline.

\section{Bacteriophage isolation}

Races of bacteriophages were isolated from pus, wastewater and other sources and were passaged systematically on the production strains of microorganisms. In addition, works were conducted to select race of phages on phage-resistant and weakly lysed strains. "Mother bacteriophage" was prepared from selected races. Upon controlling of "mother bacteriophage" according to Appelman's method, lysis occurred and activity of all selected production strains corresponded to a titer of no less than $10^{7}$.

Phage should cause specific lysis of the corresponding strain. Specific activity of the preparation according to the Appelman's method in case of staphylococci should be 106 and in case of streptococci $-10^{5}$.

The bacteriophages were isolated from waste water by filtration. Isolation of bacteriophages was carried out as follows: $100 \mathrm{ml}$ of concentrated broth was added to $90 \mathrm{ml}$ of wastewater. The required culture was added to the mixture and incubated at $37^{\circ} \mathrm{C}$ for 24 hours. After $24 \mathrm{~h}$ incubation in a thermostat, the mixture was filtered through filters with a pore diameter of 0.45 $\mu \mathrm{m}$ (Millipore, United States), and the filtrates were spot-tested for the presence of phages by application of the filtrate $(0.1 \mathrm{~mL})$ on the lawn of the test strain on a solid nutrient medium (Figure 4). 


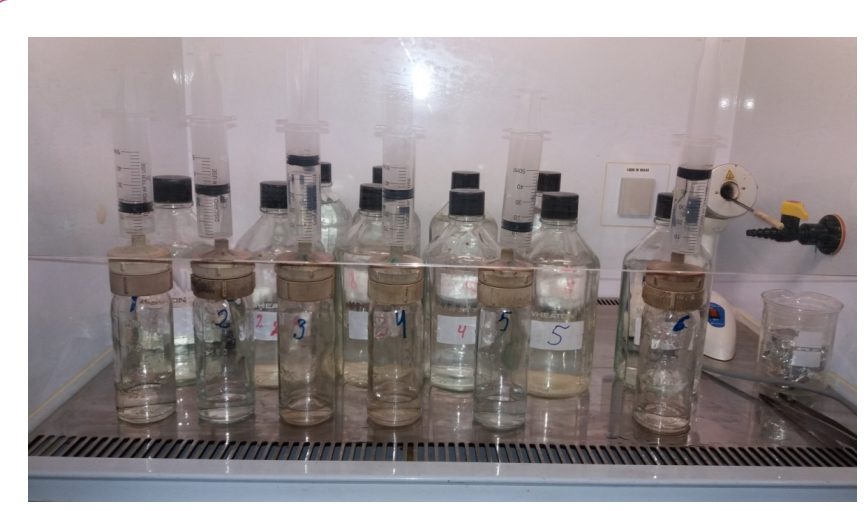

Figure 4. Wastewater filtration.

The result was considered positive if there was a lysis zone on the lawn in $18-24 \mathrm{~h}$ of cultivation at $37^{\circ} \mathrm{C}[12,13]$. The highly specific bacteriophage strains were screened and selected by the plate method according to Gracia [14].

Cultivation, concentration and purification of bacteriophages on synthetic and semisynthetic liquid media were carried out according to the regulations for the production of liquid bacteriophage. The culture was grown to a titer of $5 \times 10^{8}$ cells $/ \mathrm{ml}$, adding a phage with a multiplicity of infection of 0.2 ; aeration was continued for $8-10 \mathrm{~h}$ (aeration rate $1-2 \mathrm{l} / \mathrm{min}$ ).

The lysate was left overnight, after which chloroform (0.4\%) was added and centrifuged at $5000 \mathrm{~g}$ for $30 \mathrm{~min}$ at $+4^{\circ} \mathrm{C}$; concentration and purification of liquid lysates were carried out by two methods, either by PEG-6000 or by ion-exchange chromatography through a DEAE-cellulose column, followed by twofold differential centrifugation [15]. A total of 523 patients with periodontitis, gingivitis, stomatitis were examined.

\section{Results and Discussion}

A study of species composition of microorganisms during different human diseases isolated from oral cavity has shown the prevalence of staphylococci and streptococci over other pathogens (Table 1). Among the 745 strains isolated, 304 belonged to staphylococci, 297-to streptococci and only 144 strains-to other pathogens. The percentage ratio made up $40.8 \%, 39.9 \%$ and $19.3 \%$, respectively.

As for the intraspecific differentiation of the isolated staphylococcal strains and the studied cases, staphylococci were mainly represented by $S$. aureus and $S$. epidermidis and streptococci-by S. pyogenes, S. sanguis, S. viridians, S. salivarius, S. agalacticae.

The isolation frequency of individual types of staphylococci and streptococci was distributed as follows: $S$. aureus was most frequently diagnosed from all the organs studied-24.1\%, then $S$. epidermidis-21.8\%.

Streptococci, isolated from the oral cavity covered all the species we met: along with $S$. pyogenes and S. viridians, there were S. sanguis, S. salivarius, S. agalacticae. These species also occur in the case of mucous throat pathology. Thus, in the cases studied by us, different types of staphylococci and streptococci were found most frequently.

Along with monoinfections caused by staphylococci and streptococci, associated infections, such as intraspecific associations of staphylococci, e.g. S. aureus and S. epidermidis and streptococci, e.g. S. pyogenes, S. sanguis, S. viridians, S. salivarius, S. agalacticae, are common. In addition, an association of different genera of staphylococci and streptococci with specific variations is frequently observed.

Table 1. The basic composition of microorganisms isolated from various human organs with certain diseases.

\begin{tabular}{|c|c|c|c|c|c|c|c|c|c|c|c|c|c|c|}
\hline \multirow[t]{4}{*}{ Microorganisms } & \multicolumn{14}{|c|}{ Absolute number and percentage of isolated microorganism strains } \\
\hline & \multirow{2}{*}{\multicolumn{2}{|c|}{ Strains in all }} & \multicolumn{4}{|c|}{ Mucus } & \multicolumn{4}{|c|}{ Discharge } & \multirow{2}{*}{\multicolumn{2}{|c|}{ Vaginal }} & \multirow{2}{*}{\multicolumn{2}{|c|}{ Oral cavity }} \\
\hline & & & \multicolumn{2}{|c|}{ Nasal } & \multicolumn{2}{|c|}{ Throat } & \multicolumn{2}{|c|}{ Ear } & \multicolumn{2}{|c|}{ Eye } & & & & \\
\hline & abs & $\%$ & abs & $\%$ & abs & $\%$ & abs & $\%$ & abs & $\%$ & abs & $\%$ & abs & $\%$ \\
\hline Staphylococci & 304 & 40.8 & 38 & 13 & 58 & 19 & 51 & 17 & 53 & 17 & 48 & 16 & 56 & 18 \\
\hline Streptococci & 297 & 39.9 & 51 & 17 & 69 & 23 & 44 & 15 & 2 & 0.7 & 13 & 4 & 118 & 40.3 \\
\hline Other microorganisms & 144 & 19.3 & 11 & 7.6 & 25 & $\begin{array}{l}17 \\
.7\end{array}$ & 26 & 18 & 25 & 17.7 & 38 & 26 & 19 & 13 \\
\hline A total of & 745 & 100 & 100 & 13 & 152 & 20 & 121 & 16 & 80 & 11 & 99 & 13 & 193 & 27 \\
\hline
\end{tabular}

The study of susceptibility of microorganism strains isolated by us during different diseases to the traditionally used antibiotics and to a number of new ones of different groups has shown that presently circulating strains are characterized mainly by high level of resistance, as well as multidrug resistance to individual antibiotics (Figure 5). 


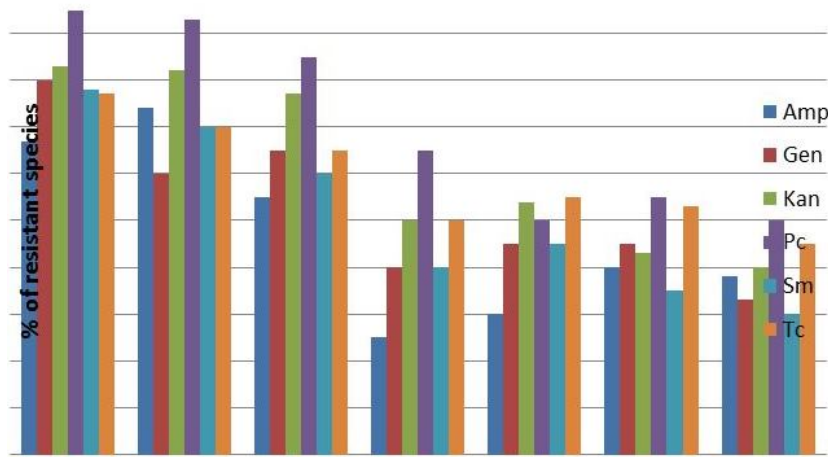

Figure 5. Sensitivity of bacterial strains to antibiotics isolated from oral cavity.

Amp-ampicillin, Gen-gentamicin, Kan-kanamicin, Pc-penicillin, Sm-streptomycin, Tc-tetracyklin.

Isolated S. aureus strains showed a certain resistance to Penicillin (95.0\%), while they were sensitive towards Ampicillin (67\%). S. epidermidis strains showed high resistance to Penicillin (93\%) and Kanamicin (82.0\%). Among the Streptococcal isolates, there was shown intermediate resistance with most of the antibiotics used in test.

The pronounced tendency of circulating strains of pathogenic bacteria with reduced sensitivity to antibiotics, caused by irrational use of the latter, further confirmed the correctness of our decision to create a new alternative phage preparation.

Proceeding from the obtained results, the presented work was aimed at the creation of a new phage preparation containing phages against the species of microorganisms isolated by us, namely, S. aureus, S. epidermidis and S. pyogenes, S. sanguis, S. viridians, S. salivarius, S. agalacticae, which cause periodontitis, gingivitis, stomatitis etc. (Figures 6-9).

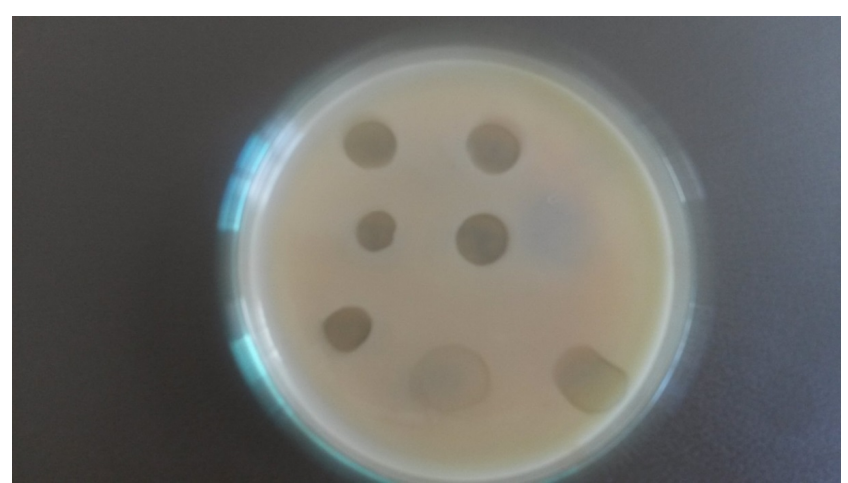

Figure 6. New phage isolated against Staphylococcus aureus strain.

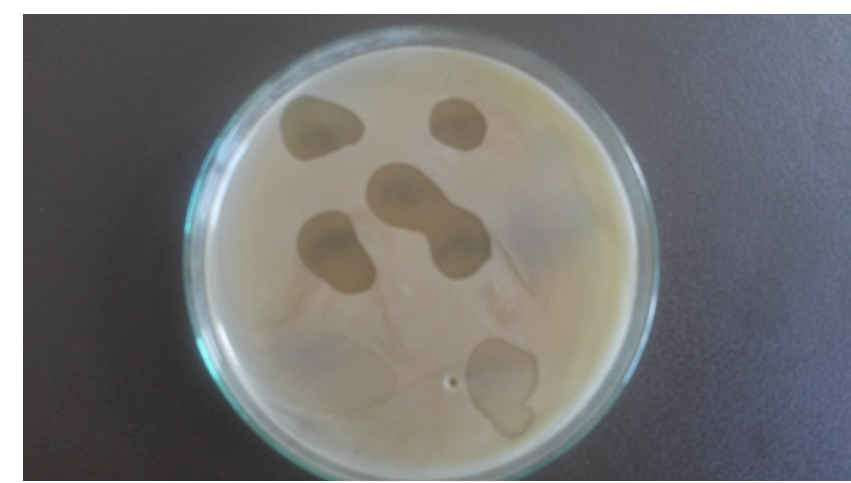

Figure 7. New phage isolated against Streptococcus pyogenes strain.

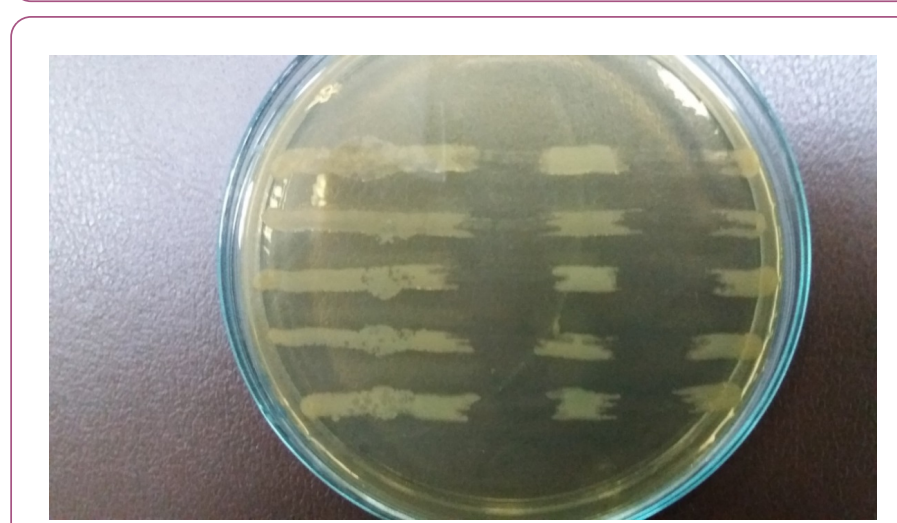

Figure 8. Sensitivity of new phage against Staphylococcus aureus strains isolated during oral infectious pathologies.

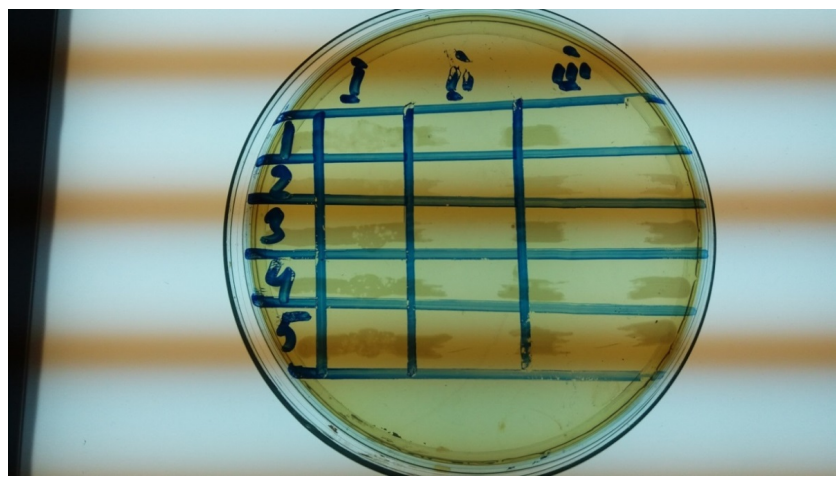

Figure 9. Sensitivity of new phage against Streptococcal pyogenes strains isolated during oral infectious pathologies.

The titers of phage preparations separately corresponded for staphylococci to $10^{6}$ and for streptococci $-10^{5}$;

In order to prepare the Fersis-diphage, thus obtained purified phagolysates with the appropriate activity were mixed and then tested for the activity both on typical strains of staphylo- and streptococci and on freshly isolated strains of the same bacteria. 
Table 2. Specific activity of bacteriophage.

\begin{tabular}{|l|l|l|}
\hline \multirow{2}{*}{ Phages } & \multicolumn{2}{|c|}{ Average titers by Appelman * } \\
\cline { 2 - 3 } & $\begin{array}{l}\text { Staphylococcal } \\
\text { strains }\end{array} * *$ & $\begin{array}{l}\text { Streptococcal } \\
\text { strains }\end{array}$ \\
\hline 1. Fersis & $10^{5}-10^{6}$ & $10^{4}-10^{5}$ \\
\hline $\begin{array}{l}\text { 2. Staphylococcal } \\
\text { component }\end{array}$ & $10^{6}$ & - \\
\hline $\begin{array}{l}\text { 3. Streptococcal } \\
\text { component }\end{array}$ & - & $10^{5}$ \\
\hline$*$-titers are given in the inverse values; \\
\hline \multicolumn{2}{|c|}{ ** -the number of strains studied -50 (for each). } \\
\hline
\end{tabular}

The results of the investigation of the specific activity of the phage components, used to control the Fersis-phage and the product, are presented in Table 2. As can be seen, in the Fersisphage, the titres of both the staphylo- and streptococcal components were by a factor of ten higher than in individual cases.

The next stage of the study was to determine the phage sensitivity of freshly isolated strains of staphylococci and streptococci. The results are shown in Table 3. A high degree of sensitivity of staphylococcal strains (S. aureus, S. epidermidis) to both the Fersis-phage and the staphylococcal component was found $-75-77 \%$ and $72-74 \%$, respectively. There was also observed pronounced sensitivity of $S$. pyogenes, S. viridians, $S$. sanguis-69-70\% and 65-62\%, respectively, while $S$. salivarius, $S$. agalacticae had less sensitivity-50-60\% and 50\%, respectively.

Table 3. Phage sensitivity of staphylococcal and streptococcal bacterial strains isolated during certain human diseases.

\begin{tabular}{|c|c|c|c|c|c|c|c|}
\hline \multirow{3}{*}{ Bacteria } & \multirow{3}{*}{ abs } & \multicolumn{6}{|c|}{ Sensitivity to bacteriophages } \\
\hline & & \multicolumn{2}{|c|}{ Staphylococcal component } & \multicolumn{2}{|c|}{ Streptococcal component } & \multicolumn{2}{|c|}{ Fersis combined } \\
\hline & & abs & $\%$ & abs & $\%$ & abs & $\%$ \\
\hline Staphylococcus & 240 & & & & & & \\
\hline S. aureus & 115 & 86 & 75 & - & - & 89 & 77 \\
\hline S. epidermidis & 103 & 74 & 72 & - & - & 70 & 74 \\
\hline Streptococcus & 210 & & & & & & \\
\hline S. pyogenes & 101 & - & - & 70 & 69 & 71 & 70 \\
\hline S. viridians & 80 & - & - & 52 & 65 & 50 & 62 \\
\hline S. sanguis & 15 & - & - & 11 & 70 & 10 & 70 \\
\hline S. salivarius & 10 & - & - & 5 & 50 & 4 & 60 \\
\hline S. agalacticae & 4 & - & - & 2 & 50 & 2 & 50 \\
\hline
\end{tabular}

\section{Morphological characteristics of phages}

Electron microscopy study of phages involving in Fersis phage preparation allowed classifying them (Figures 10 and 11). Staphylococcus aureus phage 15 had a tubular tail with helical symmetry and the diameter of $15 \mathrm{~nm}$. The tail length of the phage was $12.5 \mathrm{~nm}$, and the head diameter of $65 \mathrm{~nm}$. This phage was referred to Myoviridae family. Phages Staphylococcus aureus phage 23, Streptococcus pyogenes phage 1 and Streptococcus pyogenes phage 2 had relatively thin, long, noncontractile, and flexible tail with an isometric head. The tail length of these phages varied between 20-34 nm, a head diameter was in a range of $60-95 \mathrm{~nm}$. They were referred to Siphoviridae family.

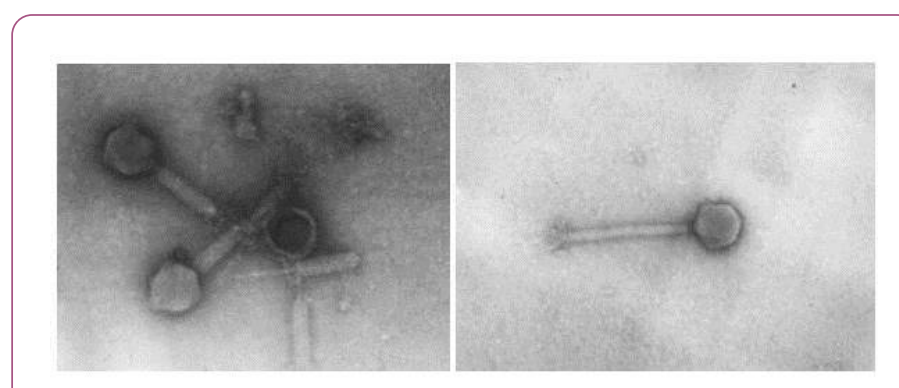

Figure 10. Staphylococcus aureus phages 15 and 23 (Electronic microscopy image). 


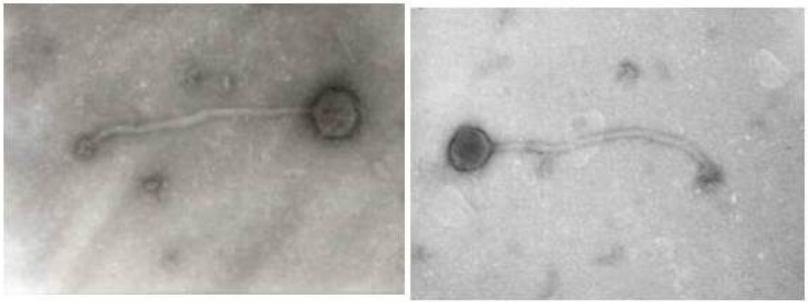

Figure 11. Streptococcus pyogenes phage 1 and 2 phages (Electronic microscopy image).

Thus, based on the studies conducted, staphylococcal and streptococcal infections prevailed in a number of human diseases. These microbes were represented by the species: $S$. aureus, S. epidermidis, S. pyogenes, S. sanguis, S. viridians, S. salivarius, S. agalacticae.

The presence of these bacteria in a number of diseases such as periodontitis, gingivitis, stomatitis etc., both separately and in combination, and a high resistance of pathogens to antibiotics, served as the basis for creating of Fersis, a new version of active, polyvalent phage preparation consisting of staphylo- and strepto phages, successfully applicable for treatments and prevention infectious diseases caused by Staphylococcus and Streptococcus genera.

\section{References}

1. Liang B, Mai J, Liu Y (2018) Prevalence and Characterization of Staphylococcus aureus Isolated From Women and Children in Guangzhou, China. Front Microbiol 16: 2790.

2. Gisch N, Auger JP, Thomsen S (2018) Structural analysis and immunostimulatory potency of lipoteichoic acids isolated from three Streptococcus suis serotype 2 strains. J Biol Chem 293: 12011-12025.

3. Singh AK, Mahlios J, Mignot E (2013) Genetic association, seasonal infections and autoimmune basis of narcolepsy. J Autoimmun 43: 26-31.
4. Barrow RA, Soothill JS (1997) Bacteriophage therapy and prophylaxis: rediscovery and renewed assessment of potential. Trends in Microbiol 5: 268-271.

5. Lu TK, Koeris MS (2011) The next generation of bacteriophage therapy. Curr Opin Microbiol 14: 524-531.

6. Chan BK, Abedon ST, Loc-Carrillo C (2013) Phage cocktails and the future of phage therapy. Future Microbiol 8: 769-783.

7. McGann P, Snesrud E, Maybank R, Corey B, Ong AC, et al. (2016) Escherichia coli Harboring MCR-1 and bla CTX-M on a Novel IncF Plasmid: First report of MCR-1 in the United States. Antimicrob. Agents Chemother 60: 4420-4421.

8. Ledeberg J (1996) Smaller fleas ... ad infinitum: therapeutic bacteriophage redux. PNAS 93: 3167-3168.

9. Levin BR, Bull JJ (1996) Phage Therapy Revisited: The Population Biology of a Bacterial Infection and Its Treatment with Bacteriophage and Antibiotics. J The American Naturalist 147: 881-898.

10. Merill C, Adhya S (1996) Long-circulating bacteriophage as antibacterial agents. PNAS 93: 3188-3192.

11. Sulakvelidze A, Alavidze Z, Morris JG (2001) Bacteriophage Therapy. Antimicrobial Agents and Chemotherapy 45: 649-659.

12. Joo EJ, Choi JY, Chung DR (2016) Characteristics of the communitygenotype sequence type 72 methicillin-resistant Staphylococcus aureus isolates that underlie their persistence in hospitals. J Microbiol 54: 445-450.

13. Yoshizawa S, Tateda K, Saga T (2012) Virulence-suppressing effects of linezolid on methicillin-resistant Staphylococcus aureus: possible contribution to early defervescence. Antimicrob Agents Chemother 56: 1744-1748.

14. Gracia A (1936) Internationaler Mathematiker-Kongreß. Ann Inst Pasteur 57: 652-657.

15. Yamamoto KR, Alberts BM, Benziger R (1970) Rapid bacteriophage sedimentation in the presence of polyethylene glycol and its application to large-scale virus purification. Virology 40: 734-744. 